\title{
Nematicidal activity of Annona crassiflora leaf extract on Caenorhabditis elegans
}

\author{
Alan Rodrigues Teixeira Machado ${ }^{1 *}$, Sebastião Rodrigo Ferreira², Felipe da Silva Medeiros ${ }^{1}$, Ricardo Toshio Fujiwara ${ }^{2}$, \\ José Dias de Souza Filho ${ }^{1}$ and Lúcia Pinheiro Santos Pimenta ${ }^{1}$
}

\begin{abstract}
Background: The aim of this work was to investigate the potential nematicidal activity of Annona crassiflora leaf extract against Caenorhabditis elegans.

Methods: The hydroalcoholic leaf extract and its fractions (dichloromethane, ethyl acetate, methanol and water) were submitted to mobility assay against the roundworm Caenorhabditis elegans. GC-MS and NMR analysis were performed in order to identify metabolites.

Results: The dichloromethane and ethyl acetate fractions showed to be the most active among the hydroalcoholic leaf extracts and its four fractions. The percentages of C. elegans larvae immobility were 98.13 and 89.66\%, respectively, at a concentration of $1000 \mu \mathrm{g} \cdot \mathrm{mL}^{-1}$. Besides some amino acids, palmitic acid methyl ester, 2-isopropyl-5-methylcyclohexanol, oleic acid methyl esther, stearic acid methyl ester, quercetin and kaempferol were also identified in these fractions.

Conclusion: The results indicated that of A. crassiflora leaf ethanolic extract has a good potential as a source for natural nematicide.
\end{abstract}

Keywords: Annona crassiflora, Caenorhabditis elegans, Metabolite, Nematicidal activity

\section{Background}

Parasitism attributed to nematodes is a worldwide problem that can negatively affect livestock, human health and plant growth. In animal breeding it can result in stunted growth, lower herd weight gain and can negatively influence meat quality. Sometimes, depending on the severity of the infection, it may lead to animal death $[1,2]$. Regarding plant production, nematodes are highlighted for causing major economic losses to agriculture [3]. The most widespread form of nematode control is that performed with synthetic anthelmintics. However, their improper use has favored the selection of resistant strains, besides being toxic and impactful to the environment [4]. In the last decade there has been an increasing search for new methods of controlling animal and plant parasitic nematodes, using methods less toxic to the environment and to people [3]. Among these, the search for compounds from natural sources stands out.

* Correspondence: alanvisconde@ufmg.br

'Departamento de Química, Instituto de Ciências Exatas, Universidade Federal de Minas Gerais, Av. Antônio Carlos 6627, Belo Horizonte, MG 31270-901, Brazil

Full list of author information is available at the end of the article
Diverse genera of plants have shown their potential as sources of various metabolites to be used in nematode control [3]. Among these, the genus Annona may be cited because the extracts of different species of this genus have shown nematicidal activity against various nematodes, such as Haemonchus sp., Bursaphelenchus sp. and Meloidogyne sp. [5-7]. Annona crassiflora Mart is a native tree from the Brazilian Cerrado, which presents various bioactive compounds [8,9]. However, its nematicidal potential has not been investigated. Therefore, the present study aimed to evaluate the in vitro activity of the extracts of $A$. crassiflora on the free-living nematode Caenorhabditis elegans as a model, to identify metabolites of $A$. crassiflora with nematicidal properties which can be of great value for the development of new products for nematode control.

\section{Methods}

General experimental procedures

The NMR spectra (one - and two-dimensional) were obtained in Bruker AVANCE DRX400 spectrometer. The solvents and reagents used were analytical grade. 
Column chromatography (CC) was performed on silica gel 70-230 $\mu \mathrm{m}$ from Sigma-Aldrich. TLC was performed on $\mathrm{SiO}_{2}$ plates (Sigma-Aldrich, $0.25 \mathrm{~mm}$ ) with visualization under UV lamp (254 and $365 \mathrm{~nm}$ ) and vanillin/ sulfuric acid as spray reagent.

\section{Plant material}

Annona crassiflora leaves were collected in Itatiaiuçu, Minas Gerais, Brazil, in July 2007. A voucher specimen was deposited at the Instituto de Ciências Biológicas Herbarium (BHCB, $\mathrm{n}^{\circ}$ 22.988), Universidade Federal de Minas Gerais.

\section{Extraction and characterization of metabolites by NMR spectroscopy}

According to the methodology described by Kim et al., [10], $50 \mathrm{mg}$ of dried, ground leaves underwent extraction with a combination of $0.75 \mathrm{~mL}$ of $\mathrm{KH}_{2} \mathrm{PO}_{4}$ buffer solution in $\mathrm{D}_{2} \mathrm{O}(90 \mathrm{mM}, \mathrm{pH}=6.0)$ containing $0.01 \%$ trimethylsilylpropionic acid (TSP- $d_{4}$ ) as internal reference and $0.75 \mathrm{~mL}$ methanol- $d_{4}$. After solvent addition, samples were vortexed for 1 minute at room temperature, followed by sonication for $20 \mathrm{~min}$ and centrifugation at $10968 \times g$ for $15 \mathrm{~min} .800 \mu \mathrm{L}$ of supernatant was transferred to $5 \mathrm{~mm}$ NMR tubes. Identification of metabolites signals on the ${ }^{1} \mathrm{H}$ NMR spectra was carried out comparing the signals observed in the hydrogen spectrum with the reported ${ }^{1} \mathrm{H}$ NMR signals of compounds available in the literature obtained under the same condition [11-14].

The ${ }^{1} \mathrm{H}-{ }^{1} \mathrm{H} J$-resolved spectrum was acquired using ns 8, tdF1 256, tdF2 $1 \mathrm{~K}$ sw F2 $4.0 \mathrm{kHz}, \mathrm{swF} 180 \mathrm{~Hz}$ and d1 1.0 s. Datasets were zero filled to 1096 points in F1 and both dimensions were multiplied by sine-bell function $(\mathrm{SSB}=0)$ prior to double complex Fourier transform. The $J$-resolved spectra were tilted by $45^{\circ}$, symmetrized about F1, and calibrated to TMS, using topspin (version 3.1, Bruker). The ${ }^{1} \mathrm{H}-{ }^{1} \mathrm{H}$ COSY experiment was acquired with a $1.0 \mathrm{~s}$ relaxation delay and $8.0 \mathrm{kHz}$ spectral width in both dimensions.

\section{Extraction and isolation of metabolites}

The dried and ground leaves $(500 \mathrm{~g})$ were subjected to exhaustive extraction by percolation with hexane at room temperature, followed by hydroalcoholic solution $\left(\mathrm{CH}_{3} \mathrm{CH}_{2} \mathrm{OH}: \mathrm{H}_{2} \mathrm{O}, 8 / 2\right)$. The extracts were concentrated under reduced pressure to obtain the crude hexane extract $(2.3 \% \mathrm{w} / \mathrm{w})$ and the crude hydroalcoholic extract $(35.2 \% \mathrm{w} / \mathrm{w})$. Approximately $10 \mathrm{~g}$ of hydroalcoholic extract was suspended in water and partitioned with solvents of increasing polarity, obtaining, after solvent removal, the following fractions and their yields: dichloromethane $(1.7 \% \mathrm{w} / \mathrm{w})$, ethyl acetate $(1.5 \% \mathrm{w} / \mathrm{w})$, methanol $(89.7 \% \mathrm{w} / \mathrm{w})$ and water $(3.2 \% \mathrm{w} / \mathrm{w})$. All fractions were tested for nematicidal activity for selection of the material to be purified. Those that showed better results were subjected to fractionation on silica gel column chromatography eluted by step gradient with hexane/ ethyl acetate from $5 \%$ to $100 \%$.

\section{GC-MS analysis}

The GC-MS analyses were performed on gas chromatography-mass spectrometer Shimadzu GCMSQP2010 Plus, equipped with an AOC-10 automatic injection system. The analyses were performed using a Rxi-1 capillary column $(30 \mathrm{~m} \times 0.25 \mathrm{~mm}$, coated with100\% polydimethylsiloxane $0.25 \mu \mathrm{m}$ film thickness) and $\mathrm{He}$ (helium) as carrier gas (flow rate $7.2 \mathrm{ml} / \mathrm{min}$ ). The injector temperature was $250^{\circ} \mathrm{C}$, and the temperature program ranged from $150^{\circ} \mathrm{C}$ to $300^{\circ} \mathrm{C}$ at $3^{\circ} \mathrm{C} / \mathrm{min}$. The injected volume was $1 \mu \mathrm{L}$, in split-mode at a ratio of 10:1. MS analysis was carried out in quadrupole MS system (QP-2010plus) operating at $70 \mathrm{eV}$ under the same conditions as described above. The identification of the compounds was performed by comparison with mass spectral data from NIST 62 and NIST 12 libraries.

\section{Methyl esters synthesis}

$150 \mathrm{~mL}$ round bottom flask equipped with reflux condenser was charged with palmitic acid (1 g), hexane $(20 \mathrm{~mL})$ and methanol containing 2,0\% (v/v) concentrated $\mathrm{H}_{2} \mathrm{SO}_{4}$. The reaction mixture was stirred and refluxed for $1 \mathrm{~h}$. The progress of the reaction was monitored by TLC, CG-MS and ${ }^{1} \mathrm{H}$ NMR. After the reaction was complete, the reaction mixture was washed with aqueous sodium chloride $10 \%(\mathrm{w} / \mathrm{v})$. The organic layer was removed, dried over anhydrous $\mathrm{Na}_{2} \mathrm{SO}_{4}$ and concentrated under vacuum. The same procedure was repeated with myristic acid and stearic acid.

\section{C. elegans production}

The strain of $C$. elegans used in the experiment was kindly provided by Universidade de São Paulo (USP). L3 larvae of C. elegans were grown on 8P NGM plates according to the methodology previously described $[15,16]$. After seven days of culture in a BOD incubator at $20^{\circ} \mathrm{C}$, the plates were washed with M9 medium (Stiernagle 2006) and filtered through three sieves with $40 \mu \mathrm{m}$, $30 \mu \mathrm{m}$ and $20 \mu \mathrm{m}$ pores. L3 larvae retained in the $20 \mu \mathrm{m}$ strainer were collected by backwashing. The obtained larvae were washed by centrifugation at $700 \mathrm{~g}$ for $4 \mathrm{mi}-$ nutes, followed by two washes with M9 medium. The average size of these larvae was $527 \mu(\sigma 3.4)$ long by $23.3 \mu$ in diameter $(\sigma 1.9)$.

\section{Nematicidal assay against $C$. elegans}

The C. elegans L3 were resuspended in M9 and approximately 1000 larvae in $100 \mu \mathrm{L}$ of suspension were added to each well in a 96 wells micro plate. Tested extracts 
and substances were dissolved in $1.0 \mathrm{~mL}$ of an aqueous $1 \%(\mathrm{v} / \mathrm{v})$ DMSO, were then added at the concentrations $0.01 ; 0.1 ; 1 ; 10 ; 100$ and $1000 \mu \mathrm{g} \cdot \mathrm{mL}^{-1}$. Plates containing extracts or substances and larvae were stored in BOD incubator at $20^{\circ} \mathrm{C}$. After 72 hours, $10 \mu \mathrm{L}$ of solution containing approximately 100 larvae was removed from each well for analysis and quantification of paralyzed larvae number was carried out using an optical microscope at 100× magnification. Larvae were considered paralyzed when presenting straight body and absence of any mobility.

\section{Statistical analyses}

Values were submitted to analysis of variance (ANOVA), followed by means separation using the Scott-Knott test $(P \leq 0.05)$. For this purpose, the software SISVAR (Sistema para análises Estatísticas, Versão 5.1, UFLA, Lavras, 2006). Nonlinear regression analysis was used to calculate the $\mathrm{ED}_{50}$ value utilized of a sigmoid curve using.

\section{Assessment of $C$. elegans larval viability}

After 72 hours exposure to 2-isopropyl-5-methylcyclohexanol the $C$. elegans larvae were treated with the fluorometric markers propidium iodide (Invitrogen) or Sytox (Invitrogen) and observed in a fluorescence microscope in order to verify the larvae viability. These markers were used at the following concentrations: $5.0 \mu \mathrm{molL}^{-1}$ and $20.0 \mu \mathrm{molL}^{-1}$ of Sytox and propidium iodide, respectively $[17,18]$. Images were taken at microscope (Leica DM500) under 100× magnification; excitation at 510-560 nm and emission at $590 \mathrm{~nm}$ for propidium iodide, excitation at 450-490 nm and emission at $535 \mathrm{~nm}$ for Sytox. The capture system used was Canon EOS 600D.

\section{Results}

Initially, the crude leaf extract of the of $A$. crassiflora was analyzed by ${ }^{1} \mathrm{H}$ NMR and characteristic amino acid and organic acid signals were observed in the $\delta 0.80$ to 4.00 region. Most of the signals ranging from $\delta 4.00$ to $\delta 5.50$ were attributed to the anomeric protons of carbohydrates, and signals at $\delta 5.50$ to 8.50 to the signals of aromatic compounds. Comparing our NMR data with the data of the ${ }^{1} \mathrm{H}$ NMR signals of metabolites available in the literature [11-14], and performing $J$-resolved and COSY analysis, it was possible to identify various compounds in a single analysis (Table 1).

Hydroalcoholic extract activity was observed in the Caenorhabditis elegans mobility test, (Table 2). As trigonelline was identified in the hydroalcoholic extract, and it is well known that trigonelline plays an important role in the resistance process of plants against several pathogens [19], commercial standard trigonelline was tested in the same assay. No significant reduction in the
Table 1 Identified metabolites in Annona crassiflora extracts

\begin{tabular}{ll}
\hline Substances & $\begin{array}{l}\text { Chemical shift }(\boldsymbol{\delta}) ; \text { multiplicity; } \\
\text { [coupling constant }(\mathbf{J} / \mathrm{Hz})]\end{array}$ \\
\hline Alanine & $1.48 ; \mathrm{d} ;[7.2]$ \\
Threonine & $1.32 ; \mathrm{d} ;[6.6]$ \\
Valine & $1.00 ; \mathrm{d} .[7.0] ; 1.05 ; \mathrm{d} ;[7.0] ; 2.3 ; \mathrm{m}$ \\
Choline & $3.24 ; \mathrm{s}$ \\
Sacarose & $5.40 ; \mathrm{d} ;[3.8] ; 4.17 ; \mathrm{d} ;[8.5]$ \\
a -glucose & $5.18 ; \mathrm{d} ;[3.8]$ \\
$\beta$-glucose & $4.58 ; \mathrm{d} ;[7.8]$ \\
Ferulic acid & $7.56 ; \mathrm{d} ;[15.9] ; 7.19 ; \mathrm{d} ;[2.1] ; 7.10 ; \mathrm{dd} ;$ \\
& {$[8.4 \mathrm{and} 2.1] ; 6.88 ; \mathrm{d} ;[8.4] ; 7.15 ; \mathrm{d} ;[2.8] ;$} \\
Formic acid & $6.33 ; \mathrm{d} ;[15.9]$ \\
Y- aminobutyricacid (GABA) & $8.46 ; \mathrm{s}$ \\
Quercetin & $2.30 ; \mathrm{t} ;[7.2] ; 3.01 . \mathrm{t} ;[7.5]$ \\
& $7.70 ; \mathrm{d} ;[2.0] ; 7.66 ; \mathrm{dd} ;[8.6$ and 2.0$] ;$ \\
Trigonelline & $6.99 ; \mathrm{d} ;[8.6] ; 6.52 ; \mathrm{d} ;[2.0] ; 6.32 ; \mathrm{d} ;[1.8]$ \\
\hline
\end{tabular}

mobility of Caenorhabditis elegans larvae was observed for trigonelline. From this result, the extract was subjected to partition with $\mathrm{CH}_{2} \mathrm{Cl}_{2}$, ethyl acetate, $\mathrm{MeOH}$ and $\mathrm{H}_{2} \mathrm{O}$, which were submitted to biological evaluation. It was observed that activity was concentrated in the ethyl acetate and dichloromethane fraction (Table 2).

Dichloromethane and ethyl acetate fractions were analyzed by TLC and ${ }^{1} \mathrm{H}$ NMR, which indicated a similar metabolic profile. As a result, these fractions were combined and fractionated in $\mathrm{SiO}_{2}$ column, from which were obtained the flavonoids quercetin and kaempferol. The latter had their structures confirmed by comparison of the ${ }^{1} \mathrm{H}$-NMR data with data obtained in the literature [20-23]. In addition, an oil was obtained and was analyzed by gas chromatography-mass spectrometry (GC-MS) and one and two-dimensional NMR. Methyl palmitate ester was identified as the major compound,

Table 2 Percentage of Caenorhabditis elegans larvae paralyzed after exposure to $A$. crassiflora extracts

\begin{tabular}{ll}
\hline $\begin{array}{l}\text { Extract, fractions and } \\
\text { compounds (1000 } \boldsymbol{\mu g} \cdot \mathbf{m L}^{-\mathbf{1}} \text { ) }\end{array}$ & Immobile nematodes (\%) \\
\hline Hydroalcoholic extract & $78.56 \mathrm{~d}$ \\
Aqueous fraction & $66.16 \mathrm{C}$ \\
Methanolic fraction & $43.53 \mathrm{~b}$ \\
Ethylacetate fraction & $89.66 \mathrm{e}$ \\
Dichloromethane fraction & $98.13 \mathrm{e}$ \\
Trigonelline & $10.06 \mathrm{a}$ \\
Negative control (DMSO 1\% v/v) & $4.66 \mathrm{a}$ \\
Positive control (Ivermectin) & $100.00 \mathrm{e}$ \\
\hline
\end{tabular}

${ }^{a}$ Means followed with the same letter do not differ significantly according to the Scott-Knott test $(P \leq 0.05)$. 
as well as some minor compounds identified by the NIST libraries, considering the compounds with similarity index equal to or greater than $85 \%$ (Table 3 ).

The oil and the three methyl esthers identified, as well as the 2-isopropyl-5-methylcyclohexanol were evaluated through the mobility test with $C$. elegans. The results indicated that the larvae mobility percentage was directly proportional to the oil and 2-isopropyl-5-methylcyclohexanol concentration (Figure 1). The $\mathrm{ED}_{50}$ values, after 72 hours, for oil and 2-isopropyl-5-methylcyclohexanol were 350 and $113 \mu \mathrm{g} \cdot \mathrm{mL}^{-1}$, respectively. The three methyl esters did not show any significant activity.

The C. elegans larvae treated with 2-isopropyl-5methylcyclohexanol after 72 hour exposure to the substance at concentration $1000 \mu \mathrm{g} \cdot \mathrm{mL}^{-1}$, were efficiently stained with propidium iodide and Sytox (Figure 2).

\section{Discussion}

Different species of Annona have shown nematicidal effects. In in vitro assay it was observed that the aqueous extract of Annona senegalensis caused a significant reduction in the development of Haemonchus contortus nematode eggs [5]. Dang et al., [6] also confirmed the nematicidal effect of methanolic and ethyl acetate extracts of Annona squamosa seeds against the plant-parasitic nematodes Meloidogyne incognita and Bursaphelenchu sxylophilus. In a recent paper, Ferreira and colleagues [7] demonstrated the efficacy of the aqueous extract of Annona muricata against eggs, larvae and adult worms of Haemonchus contortus. The present study revealed that the Annona crassiflora leaf extract, dichloromethane and ethyl acetate fractions showed high activity against $C$. elegans when compared with the synthetic positive control. This potent nematicidal action observed in the hydroalcoholic extract could be due to the known potent nematicidal compounds present in it. Important metabolites are formic acid, toxic on nematodes exposed [24], and $\gamma$-aminobutyric acid, which can cause paralysis of nematode muscles [25]. Trigonelline, also identified in the extract, plays an important role in plant resistance to pathogen attack. It is also worth noting the inhibitory activity of trigonelline against enzyme acetylcholinesterase

Table 3 Chemical composition of the oil isolated from Annona crassiflora leaves

\begin{tabular}{lll}
\hline Compounds & $\begin{array}{l}\text { Retention } \\
\text { time (min) }\end{array}$ & Percentage (\%) \\
\hline Palmitic acid methyl esther (1) & 6.24 & 48.14 \\
2-isopropyl-5-methylcyclohexanol (2) & 6.56 & 2.39 \\
y-Dodelactone (3) & 6.72 & 3.94 \\
Palmitic acid ethyl esther (4) & 6.83 & 5.20 \\
Oleic acid, methyl esther (5) & 7.75 & 7.74 \\
Stearic acid methyl esther (6) & 7.99 & 11.60 \\
\hline
\end{tabular}

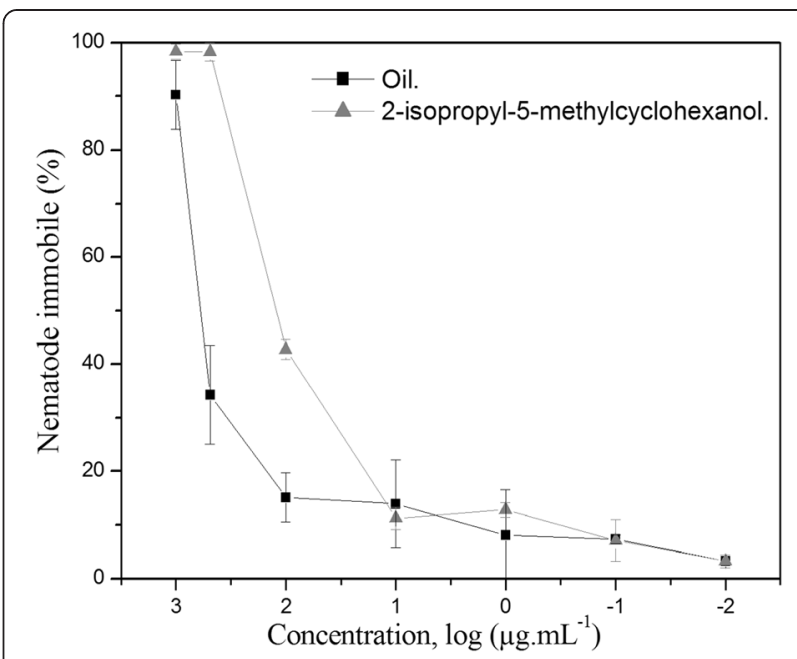

Figure 1 Effect of oil isolated from the leaves of Annona crassiflora and 2-isopropyl-5-methylcyclohexanol on mobility of Caenorhabditis elegans.

[26], an enzyme that acts on termination of nerve impulses and is the target of several commercial nematicides. Thus, a positive result for trigonelline in C. elegans mobility test was expected. However, in the present study this compound was not active against this nematode (Table 2).

The chemical characterization of the isolated oil from the dichloromethane and ethyl acetate fractions revealed the presence of several compounds of fatty nature, being methyl palmitate the major compound. Gu and colleagues [27] reported no effect of methyl palmitate and ethyl stearate, at a concentration of $150 \mu \mathrm{g} \cdot \mathrm{mL}^{-1}$, on the mobility of C. elegans. In our bioassays the methyl palmitate enriched oil fraction caused immobility of nematodes at an $\mathrm{ED}_{50}$ of $350 \mu \mathrm{g} \cdot \mathrm{mL}^{-1}$. Thus, it is possible that the minor compounds of the oil can induce the nematicidal activity observed. In fact, studies with C. elegans have demonstrated that 2-isopropyl-5-methylcyclohexanol and other monoterpenes have nematicidal activity superior to the commercial nematicide Oxamyl [28]. Furthermore, the analysis of staining test with propidium iodide and Sytox suggest that not only 2-isopropyl-5-methylcyclohexanol causes a reduction in larvae mobility but also causes

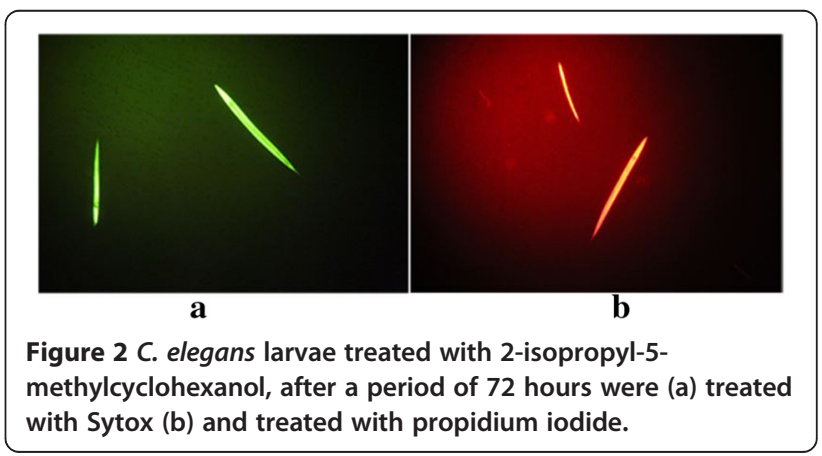


damage to cell membrane integrity and interferes in the cellular process of exogenous molecule exclusion. Both the utilized markers are nucleic acid markers, Sytox is not able to cross plasma membrane of viable cells and propidium iodide is capable of going through intact cell membranes, however it is expelled by cells that have a viable exogenous molecule excretion mechanism $[17,18]$.

\section{Conclusions}

This is the first report of nematicidal activity of A. crassiflora leaf ethanolic extract and its fractions. The results revealed this species as a promising source for the discovery of new bioactive compounds against nematodes and its hydroalcoholic extract can also be used in a formulation in order to reduce the intensive use of synthetic nematicides, thus reducing the risks to humans and to the environment.

\section{Competing interests}

The authors declare that they have no competing interests.

\section{Authors' contributions}

Conceived and designed the study: ARTM and LPSP. Performed the experiments: ARTM, FSM and SRF. Drafting of the manuscript or critical revision for important intellectual content: ARTM, LPSP, RTF and JDSF. All authors read and approved the final manuscript.

\section{Acknowledgments}

We thank FAPEMIG for their financial support (Grant CEX-APQ-01314-13), Geke Kool for English revision and CAPES for the fellowship of ARTM.

\section{Author details \\ 'Departamento de Química, Instituto de Ciências Exatas, Universidade Federal de Minas Gerais, Av. Antônio Carlos 6627, Belo Horizonte, MG 31270-901, Brazil. 'Departamento de Parasitologia, Instituto de Ciências Biológicas, Universidade Federal de Minas Gerais, Av. Antônio Carlos, 6627, Pampulha, CEP 31270-901 Belo Horizonte, Minas Gerais, Brazil.}

Received: 5 August 2014 Accepted: 31 January 2015

Published online: 19 February 2015

\section{References}

1. Waller PJ, Larsen M. The role of nematophagous fungi in the biological control of nematode parasites of livestock. Int J Parasitol. 1993;23(4):539-46.

2. Torina A, Dara S, Marino AM, Sparagano AO, Vitale F, Reale S, et al. Study of gastrointestinal nematodes in sicilian sheep and goats. Ann N Y Acad Sci. 2004;1026:187-94.

3. Chitwood DJ. Phytochemical based strategies for nematode control. Annu Rev Phytopathol. 2002;40:22-49.

4. Caboni P, Ntalli NG, Aissani N, Cavoski I, Angioni A. Nematicidal activity of (E, E)-2,4-decadienal and (E)-2-decenal from Ailanthus altissima against Meloidogyne javanica. J Agric Food Chem. 2012;60(4):1146-51.

5. Alawa CBI, Adamu AM, Gefu JO, Ajanusi OJ, Abdu PA, Chiezey NP, et al. In vitro screening of two Nigerian medicinal plants (Vernoni amygdalina and Annona senegalesis) for anthelmintic activity. Vet Parasitol. 2003;113(1):73-81.

6. Dang QL, Kim WK, Nguyen CM, Choi YH, Choi GJ, Jang KS, et al. Nematicidal and antifungal activities of annonaceous acetogenins from Annona squamosa against various plant pathogens. J Agric Food Chem. 2011;59(20):11160-7.

7. Ferreira LE, Castro PMN, Chagas ACS, França SC, Beleboni RO. In vitro anthelmintic activity of aqueous leaf extract of Annona muricata $\mathrm{L}$. (Annonaceae) against Haemonchus contortus from sheep. Exp Parasitol. 2013;134(3):327-32.

8. Pimenta LPS, Boaventura MAD, Oliveira AB. Crassiflorina, uma acetogenina tetra-hidrofurânica citotóxica de Annona crassiflora (araticum). Quím Nova. 1994;17:387-91.
9. Pimenta LPS, Boaventura MAD, Cassady JM, Oliveira AB. Grossamide and $\mathrm{N}$-trans-caffeoyltyramine from Annona crassiflora seeds. Planta Med. 1996;62(1):76.

10. Kim HK, Choi YA, Verpoorte R. NMR-based metabolomic analysis of plants. Nat Protoc. 2010;5(3):536-49.

11. Abdel-Farid IB, Kim HK, Choi YH, Verpoorte R. Metabolic characterization of Brassica rapa leaves by NMR spectroscopy. J Agric Food Chem. 2007;55(19):7936-43.

12. Ali K, Maltese F, Zyprian E, Rex M, Choi YH, Verpoorte R. NMR metabolic fingerprinting based identification of grapevine metabolites associated with downy mildew resistance. J Agric Food Chem. 2009;57(20):9599-606.

13. Kim HK, Saifullah KS, Wilson EG, Kricun SD, Meissner A, Goraler S, et al. Metabolic classification of South American Ilex species by NMR-based metabolomics. Phytochemistry. 2010;71(7):773-84.

14. Ali K, Maltese F, Fortes AM, Pais MS, Choi YH, Verpoorte R. Monitoring biochemical changes during grape berry development in Portuguese cultivars by NMR spectroscopy. Food Chem. 2011;124(4):1760-9.

15. Brenner S. The genetics of Caenorhabditis elegans. Genetics. 1974;77(1):71-94.

16. Stiernagle T. Maintenance of C. elegans [http://www.wormbook.org/ chapters/www_strainmaintain/strainmaintain.html]

17. Gill MS, Olsen A, Sampayo JN, Lithgow GJ. An automated high-throughput assay for survival of the nematode Caenorhabditis elegans. Free Radical Biol Med. 2003;35(6):558-65.

18. Hunt PR, Olejnik N, Sprando RL. Toxicity ranking of heavy metals with screening method using adult Caenorhabditis elegans and propidium iodide replicates toxicity ranking in rat. Food Chem Toxicol. 2012;50(9):3280-90.

19. Tyihak E, Sarhan ART, Cong NT, Barna B, Kiraly Z. The level of trigonelline and other quaternary ammonium compounds in tomato leaves in ratio to the changing nitrogen supply. Plant and Soil. 1978;109:285-7.

20. Dhasan PB, Jegadeesan M, Kavimani S. Cucurbitacins isolated from the fruits of Momordica cymbalaria Hook f. Phcog Mag. 2008;4(14):96-101.

21. Abdel-Sattar E, Abd El-Monem AR, Sleem AA. Biological and chemical study of Cleome paradoxa B. Pharmacognosy Research. 2009;1(4):175-8.

22. Thakur A, Jain V, Hingorani L, Laddha KS. Phytochemical studies on Cissus quadrangularis Linn. Pharmacognosy Research. 2009;1(4):213-5.

23. Adebayo AH, Tan NH, Akindahunsi AA, Zeng GZ, Zhang YM. Anticancer and antiradical scavenging activity of Ageratum conyzoides L. (Asteraceae). Pharmacogn Mag. 2010;6(21):62-6.

24. Djian C, Ponchet M, Cayrol JC. Nematocidal properties of carboxylic acids and derivatives. Pest Biochem Physiol. 1994;50(3):229-39.

25. Perry RN, Maule AG. Physiological and biochemical basis behavior. In: Gauler R, Bilgrami L, editors. Nematode Behavior. New Jersey: CABI Publishing; 2004. p. 197-238.

26. Satheeshkumar N, Mukherjee PK, Bhadra S, Saha BP. Acetylcholinesterase enzyme inhibitory potential of standardized extract of Trigonella foenum graecum $L$ and its constituents. Phytomedicine. 2010;17(3-4):292-5.

27. Gu JQ, Eppler CM, Montenegro G, Timmins SD, Timmermann BN. Identification of nematicidal fatty acids and triglycerides from seeds of Jubaeachilensis by GC-El-MS and chemical transformation methods. Z Naturforsch C. 2005;60(7-8):527-33.

28. Tsao R, Yu Q. Nematicidal activity of monoterpenoid compounds against economically important nematodes in agriculture. J Essent Oil Res. 2000;12(3):350-4.

\section{Submit your next manuscript to BioMed Central and take full advantage of:}

- Convenient online submission

- Thorough peer review

- No space constraints or color figure charges

- Immediate publication on acceptance

- Inclusion in PubMed, CAS, Scopus and Google Scholar

- Research which is freely available for redistribution 